\title{
Facile Hydrothermal Synthesis of Manganese Dioxide/Nitrogen- Doped Graphene Composites as Electrode Material for Supercapacitors
}

\author{
Bin Huang, Chenling Huang, Yong Qian* \\ Jiangxi Engineering Research Center of Process and Equipment for New Energy, East China \\ University of Technology, Nanchang 330013, P.R. China \\ *E-mail: yqianecit@163.com
}

doi: $10.20964 / 2017.12 .40$

Received: 6 August 2017 / Accepted: 12 October 2017 / Published: 12 November 2017

\begin{abstract}
We report a simple and efficient approach for the in-situ decoration of manganese dioxide $\left(\mathrm{MnO}_{2}\right)$ nanoparticles onto nitrogen-doped graphene (NG) using polyvinylpyrrolidone (PVP) as the dispersing agent and stabilizer. The morphology and microstructure of the as-prepared $\mathrm{MnO}_{2} / \mathrm{NG}$ composites were characterized by transmission electron microscopy and X-ray photoelectron spectroscopy. The results show that a uniform dispersion of $\mathrm{MnO}_{2}$ nanoparticles with a mean size of about 10-20 nm was successfully anchored on the NG surfaces. Furthermore, the electrochemical capacitive behaviors of the $\mathrm{MnO}_{2} / \mathrm{NG}$ hybrid materials were investigated by cyclic voltammetry (CV) and galvanostatic charge-discharge (GCD). The $\mathrm{MnO}_{2} / \mathrm{NG}$ composites delivered a high specific capacitance of $302 \mathrm{~F} / \mathrm{g}$ at $1 \mathrm{~A} / \mathrm{g}$ in $1 \mathrm{M} \mathrm{Na}_{2} \mathrm{SO}_{4}$ electrolyte; they also showed good cycling stability with $88.9 \%$ retention rate of specific capacitance after 1000 cycles of charge and discharge. This study provides a rational device for designing high-performance $\mathrm{MnO}_{2}$-based supercapacitors.
\end{abstract}

Keywords: Supercapacitor, manganese dioxide, nitrogen-doped graphene, electrode material

\section{$\underline{\text { FULL TEXT }}$}

(C) 2017 The Authors. Published by ESG (www.electrochemsci.org). This article is an open access article distributed under the terms and conditions of the Creative Commons Attribution license (http://creativecommons.org/licenses/by/4.0/). 